\title{
Sarcopenia is associated with postoperative infection and delayed recovery from colorectal cancer resection surgery
}

\author{
JR Lieffers', OF Bathe ${ }^{2}, K_{\text {Fassbender }}^{3}, M_{\text {Winget }}^{4,5}$ and VE Baracos ${ }^{*, 3}$ \\ 'Division of Human Nutrition, Department of Agricultural, Food \& Nutritional Science, University of Alberta, Edmonton, Alberta, Canada; ${ }^{2}$ Department of \\ Surgery and Oncology, University of Calgary, Calgary, Alberta, Canada; ${ }^{3}$ Division of Palliative Care Medicine, Department of Oncology, University of \\ Alberta, II 560 University Avenue, Edmonton T6G IZ2, Alberta, Canada; ${ }^{4}$ School of Public Health, University of Alberta, Edmonton, Alberta, Canada; \\ ${ }^{5}$ Community Oncology, Alberta Health Services - Cancer Care, Edmonton, Alberta, Canada
}

BACKGROUND: Skeletal muscle depletion (sarcopenia) predicts morbidity and mortality in the elderly and cancer patients. METHODS: We tested whether sarcopenia predicts primary colorectal cancer resection outcomes in stage $I-I V$ patients $(n=234)$. Sarcopenia was assessed using preoperative computed tomography images. Administrative hospitalisation data encompassing the index surgical admission, direct transfers for inpatient rehabilitation care and hospital re-admissions within 30 days was searched for International Classification of Disease (ICD)- 10 codes for postoperative infections and inpatient rehabilitation care and used to calculate length of stay (LOS).

RESULTS: Overall, 38.9\% were sarcopenic; $16.7 \%$ had an infection and $9.0 \%$ had inpatient rehabilitation care. Length of stay was longer for sarcopenic patients overall ( $15.9 \pm 14.2$ days vs $12.3 \pm 9.8$ days, $P=0.038$ ) and especially in those $\geqslant 65$ years $(20.2 \pm 16.9$ days vs $13.1 \pm 8.3$ days, $P=0.008)$. Infection risk was greater for sarcopenic patients overall $(23.7 \%$ vs $12.5 \% ; P=0.025)$, and especially those $\geqslant 65$ years $(29.6 \%$ vs $8.8 \%, P=0.005)$. Most $(90 \%)$ inpatient rehabilitation care was in patients $\geqslant 65$ years. Inpatient rehabilitation was more common in sarcopenic patients overall $(14.3 \%$ vs $5.6 \%$; $P=0.024)$ and those $\geqslant 65$ years $(24.1 \%$ vs $10.7 \%$, $P=0.06$ ). In a multivariate model in patients $\geqslant 65$ years, sarcopenia was an independent predictor of both infection (odds ratio (OR) 4.6, (95\% confidence interval $(\mathrm{Cl})$ I.5, 13.9) $P<0.01$ ) and rehabilitation care $(\mathrm{OR} 3.1(95 \% \mathrm{Cl} \mid .04,9.4) P<0.04)$. CONCLUSION: Sarcopenia predicts postoperative infections, inpatient rehabilitation care and consequently a longer LOS. British Journal of Cancer (2012) I 07, 931-936. doi:I0.1038/bjc.2012.350 www.bjcancer.com

Published online 7 August 2012

(c) 2012 Cancer Research UK

Keywords: colorectal cancer; surgery; sarcopenia; infection; rehabilitation care; length of stay

Sarcopenia, frequently defined as an absolute muscle mass $<2$ s.d. below the healthy young adult mean (Baumgartner et al, 1998), is associated with aging, inactivity and with a series of chronic diseases, including chronic renal failure, chronic obstructive pulmonary disease and cancer. Sarcopenia associates with poor physical function and nosocomial infections in non-cancer populations (Pichard et al, 2004; Cosquéric et al, 2006). Computed tomography (CT) imaging, as routinely conducted in oncology, provides a means to precisely quantify skeletal muscle (Mourtzakis et al, 2008; MacDonald et al, 2011; Baracos et al, 2012). Recently, it has been revealed that sarcopenia in cancer patients is associated with treatment toxicity, poor functional status and decreased survival (Prado et al, 2008, 2009, 2011; Antoun et al, 2010; van Vledder et al, 2012).

The numerous poor outcomes associated with sarcopenia (survival, infection, length of hospital stay, treatment toxicity, physical disability) suggest that a sarcopenic individual is generally unfit or poorly equipped to deal with stress or disease. This led us to speculate that sarcopenic individuals may have difficulty in the context of a major surgical intervention. Because infectious complications during hospitalisation have been documented in non-cancer patients with sarcopenia (Pichard et al, 2004;

*Correspondence: Dr VE Baracos; E-mail: vickie.baracos@ualberta.ca Received 4 April 2012; revised 8 July 2012; accepted I3 July 2012; published online 7 August 2012
Cosquéric et al, 2006) and because muscle function is central to physical function, we conjectured that sarcopenic patients may have a longer stay in hospital, and will be less likely to be discharged home and more likely to require inpatient rehabilitation care, following a major oncologic surgery. The aim of this study was to test for an association between sarcopenia and these outcomes, by means of a review of Administrative Health Data (hospital discharge abstracts including information recorded using International Classification of Disease (ICD) 10 codes).

\section{MATERIALS AND METHODS}

\section{Patient population}

Ethical approval was obtained from the Alberta Cancer Research Ethics Board. Our candidate population for this study was colorectal cancer patients undergoing primary tumour resection. The patient population $(n=234)$ was a consecutive cohort of Edmonton, Alberta, Canada residents with stage II-IV colorectal cancer (ICD-O codes: C18-C20 excluding appendix cancer (C18.1)) who underwent a colorectal procedure (segmental or partial colectomy, hemicolectomy, subtotal or total colectomy, sigmoid colon resection, anterior resection or abdominoperineal resection) between April 12002 and March 31 2006. Patients were identified by a search of the Alberta Cancer Registry, which codes primary 
cancers in the province of Alberta by site, morphology, clinical and demographic information. Registry records were linked with hospital discharge abstracts including information on diagnoses, procedures and outcomes using ICD-10 codes. Age, sex, cancer stage (American Joint Committee on Cancer, 7th edition), tumour site, date of surgery were obtained from the Alberta Cancer Registry. Height and weight were abstracted from records of routine clinical nutritional screening collected during consultations with the oncologist and were used to calculate the common anthropometric descriptor, body mass index (BMI).

\section{Computed tomography image analysis}

Computed tomography scans taken for planning surgery were chosen; they were taken on average 31 days prior to surgery. Images were retrieved from digital storage in the Picture Archiving and Communication System. Computed tomography image analysis (Slice-O-Matic V4.3 software (Tomovision, Montreal, Canada)), was performed as described previously (Mourtzakis et al, 2008). Briefly, total skeletal muscle and adipose tissue surface area $\left(\mathrm{cm}^{2}\right)$ were evaluated on a single image at the third lumbar vertebrae (L3) using Hounsfield unit thresholds of -29 to +150 for skeletal muscle, -150 to -50 for visceral adipose tissue and -190 to -30 for subcutaneous and intermuscular adipose tissues. Skeletal muscle and adipose tissue area at L3 is significantly related to whole-body tissue mass in healthy adults (Shen et al, 2004) and cancer patients (Mourtzakis et al, 2008). Tissue cross-sectional area $\left(\mathrm{cm}^{2}\right)$ was computed by summing tissue pixels and multiplying by the pixel surface area; areas were normalised for stature $\left(\mathrm{m}^{2}\right)$ and reported as lumbar skeletal muscle and adipose tissue index $\left(\mathrm{cm}^{2} \mathrm{~m}^{-2}\right)$. Sarcopenia was defined using sex-specific skeletal muscle index cutpoints $\left(<38.5 \mathrm{~cm}^{2} \mathrm{~m}^{-2}\right.$ (females) and $<52.4 \mathrm{~cm}^{2} \mathrm{~m}^{-2}$ (males)) based on survival in obese cancer patients (Prado et al, 2008). These values were identified in a cancer population using a statistical test (optimal stratification) for cutpoint in relation to increased mortality. These cutoffs were accepted by an international consensus group on the diagnostic criteria for cancer cachexia (Fearon et al, 2011). The cutpoints also give clear separation of a poor survival subgroup in patients with cirrhosis (Montano-Loza et al, 2012).

\section{Administrative data}

Comorbidities were obtained from inpatient hospitalisation administrative data provided by the provincial Ministry of Health. This data set includes all inpatient hospitalisations that occurred in any Alberta hospital and includes up to 16 ICD-10 diagnostic codes for each hospitalisation. Comorbidities were identified using a validated Elixhauser coding algorithm available for ICD-10 codes (Quan et al, 2005; Lieffers et al, 2011). The index surgery hospital admission, direct transfers to other facilities following the index surgical admission and re-admissions to hospital within 30 days of discharge from the index surgical admission and any hospitalisations in the year prior to the surgical hospitalisation were searched for comorbidities. Binary variables indicating the presence or absence of each comorbidity were created with the exception for obesity and weight loss, which are not properly captured using administrative health data.

Obstruction and perforation were also identified using ICD-10 codes. Patients were considered to have presented with obstruction if the code K56.6 (other and unspecified intestinal obstruction) was reported in the index surgical hospital admission; patients were considered to have presented with perforation if the code K63.1 (perforation of intestine (non traumatic)) was present in the index surgical admission.

Data on infections and rehabilitation care following surgery were also identified from ICD-10 diagnostic codes from the inpatient hospitalisation administrative data as described above. We searched the index surgery hospital admission, direct transfers to other facilities following the index surgical admission and readmissions to hospital within 30 days of discharge from the index surgical admission for ICD-10 codes indicating evidence of an infection or a requirement for rehabilitation care.

Each hospitalisation abstract also contains dates of admission and discharge, which were subtracted from one another to calculate length of stay (LOS). Decisions regarding discharge in this population reside with the individual surgeon.

\section{Statistical analysis}

SPSS v18.0 (IBM SPSS Statistics, Ontario, Canada) was used for statistical analysis. Data are presented as mean \pm s.d. Two sample independent $t$-tests and $\chi^{2} /$ Fisher Exact tests were used to test for differences in continuous and categorical variables, respectively. Univariate and multivariate logistic regression were used to assess the relationship between sarcopenia and categorical variables. All tests were two-sided and $\alpha$ was set at 0.05 .

\section{RESULTS}

Patient characteristics are listed in Tables 1 and 2. One patient $(0.4 \%)$ died during the index surgery hospitalisation; no other patients died during admissions related to rehabilitation or re-admissions to hospital. Body weight and composition characteristics are listed in Table 1. Body mass index prior to surgery was variable and ranged from 17.5 to $48.8 \mathrm{~kg} \mathrm{~m}^{-2}$;

Table I Patient body weight and composition

\begin{tabular}{|c|c|c|c|c|}
\hline & All patients $(n=234)$ & Non-sarcopenic $(n=143)$ & Sarcopenic $(n=91)$ & $P$-value \\
\hline \multicolumn{5}{|l|}{ Body weight } \\
\hline BMI $\left(\mathrm{kg} \mathrm{m}^{-2}\right)^{\mathrm{a}}$ & $28.5 \pm 5.3$ & $30.0 \pm 5.4$ & $26.1 \pm 4.2$ & $<0.001$ \\
\hline \multicolumn{5}{|l|}{ BMl category, $n(\%)$} \\
\hline Underweight & I (0.5) & $0(0)$ & I ( 1.3$)$ & $<0.001$ \\
\hline Normal weight & $47(23.6)$ & $19(15.4)$ & $28(36.8)$ & \\
\hline Overweight & $90(45.2)$ & $53(43.1)$ & $37(48.7)$ & \\
\hline Obese & $61(30.7)$ & $51(41.5)$ & $10(13.2)$ & \\
\hline \multicolumn{5}{|l|}{ Body composition } \\
\hline Men L3 skeletal muscle index $\left(\mathrm{cm}^{2} \mathrm{~m}^{-2}\right)$ & $54.8 \pm 8.6$ & $60.3 \pm 6.7$ & $47.3 \pm 3.6$ & $<0.001$ \\
\hline Women L3 skeletal muscle index $\left(\mathrm{cm}^{2} \mathrm{~m}^{-2}\right)$ & $41.9 \pm 6.5$ & $45.5 \pm 4.7$ & $35.0 \pm 2.9$ & $<0.001$ \\
\hline Men $\mathrm{L} 3$ adipose tissue index $\left(\mathrm{cm}^{2} \mathrm{~m}^{-2}\right)^{\mathrm{b}}$ & $117.4 \pm 55.8$ & $130.4 \pm 56.5$ & $99.4 \pm 49.8$ & 0.002 \\
\hline Women $\mathrm{L} 3$ adipose tissue index $\left(\mathrm{cm}^{2} \mathrm{~m}^{-2}\right)^{\mathrm{b}}$ & $128.6 \pm 72.5$ & $142.3 \pm 75.6$ & $102.1 \pm 58.6$ & 0.007 \\
\hline
\end{tabular}

Abbreviation: $\mathrm{BMI}=$ body mass index. ${ }^{\mathrm{a} B M I}$ was not available for 35 patients ( 20 non-sarcopenic and 15 sarcopenic). ${ }^{\mathrm{b}}$ Total adipose tissue index was missing for 8 female patients and 13 male patients due to subcutaneous adipose tissue being cut off from computed tomography scan field of view. 
Table 2 Demographic and clinical factors associated with sarcopenia

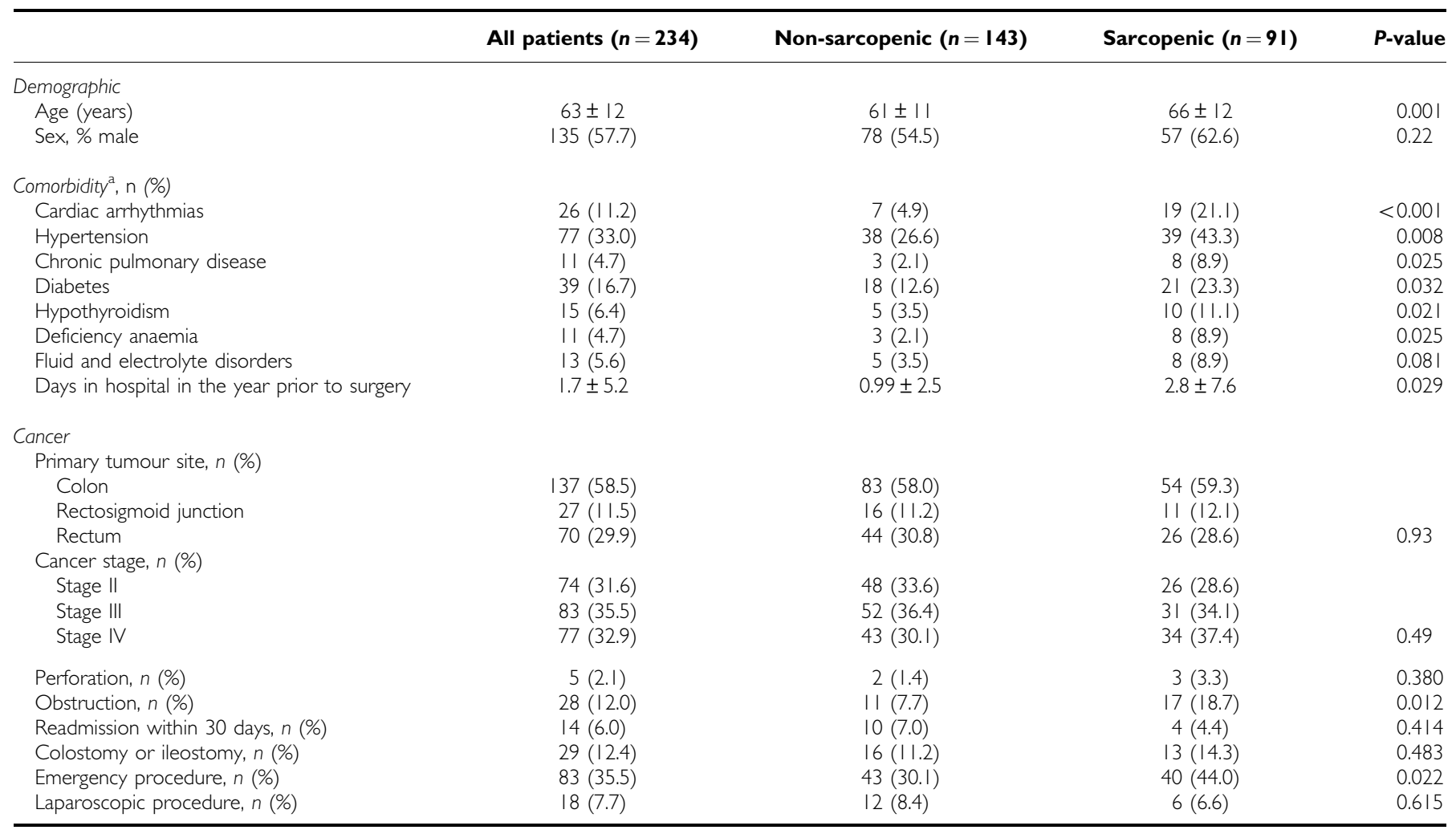

a Less than $5 \%$ of patients had the following conditions: valvular disease, pulmonary circulation disorders, peripheral vascular disease, congestive heart failure, paralysis, renal failure, liver disease, peptic ulcer disease, AIDS, rheumatoid arthritis, coagulopathy, blood loss anaemia, depression, alcohol abuse, drug abuse, psychosis. Hypertension and hypertension with complications were combined. Diabetes and diabetes with complications were combined.

the mean BMI for this cohort was in the overweight category $\left(28.5 \pm 5.3 \mathrm{~kg} \mathrm{~m}^{-2}\right)$.

Lumbar skeletal muscle index exhibited variation in both sexes (Figure 1), with the least muscular individuals having half as much muscle as the most muscular ones. Overall, 91 patients $(38.9 \%)$ were classified as sarcopenic. Sarcopenia was significantly more common in patients $\geqslant 65$ years compared with those $<65$ years $(48.6 \%$ vs $30.1 \%, P=0.004)$. Patients $<65$ years had more muscle than those $\geqslant 65$ years (women: $43.4 \pm 5.8 \mathrm{~cm}^{2} \mathrm{~m}^{-2}$ vs $40.7 \pm 6.9 \mathrm{~cm}^{2} \mathrm{~m}^{-2}, \quad P=0.042$; men: $57.0 \pm 8.9 \mathrm{~cm}^{2} \mathrm{~m}^{-2} \quad v s$ $\left.51.8 \pm 7.1 \mathrm{~cm}^{2} \mathrm{~m}^{-2}, P<0.001\right)$.

Several factors were associated with sarcopenia (Table 2). Individuals with sarcopenia were on average older, and had a lower BMI than those without sarcopenia; men and women were equally likely to present with sarcopenia. Several comorbidities were more common in individuals with sarcopenia compared with those without including cardiac arrythmias, diabetes, hypertension, deficiency anaemia, hypothyroidism and fluid and electrolyte disorders. Moreover, obstruction was more common in patients with sarcopenia and they were thus more likely to present for surgery on an emergency/urgent basis. Cancer stage, and tumour site were not associated with sarcopenia. Open ( $v s$ laparoscopic) surgical procedures and the placement of colostomy or ilieostomy were not associated with sarcopenia. There were six total coded complications (N99xx) post-procedural kidney failure, urethral stricture, post-procedural pelvic peritoneal adhesions and these were equally distributed in the sarcopenic and non-sarcopenic groups.

\section{Outcomes}

The relationship between sarcopenia and infection, requirement for rehabilitation care following surgery and LOS is reported in
Table 3. Overall, sarcopenia was related to these outcomes in all patients $(P$-values $<0.05)$. However, when examining the relationship between sarcopenia and these outcomes in younger patients only (i.e., those $<65$ years), sarcopenia was not a significant predictor. Moreover, in the case of the requirement for inpatient rehabilitation care, this was almost exclusively an outcome in patients older than 65 years. Therefore, we decided to focus our analysis and results on those $\geqslant 65$ years.

\section{Postoperative infection and inpatient rehabilitation in patients over 65 years of age}

Infections Overall, 39 patients (16.7\%) had an infection code recorded in the hospitalisation record. The following ICD-10 diagnostic codes related to infection were found: urinary tract infection (N39.0), pneumonia (J18.X), peritonitis (K65.0, K65.8), septicaemia (A41.X), infection following a procedure (T81.4), enterocolitis due to Clostridium difficile (A04.7) and diarrhoea and gastroenteritis of presumed infectious origin(A09)). Figure 1A shows the distribution of infection by skeletal muscle index and age. Patients with sarcopenia had an infection code recorded more frequently than those without sarcopenia $(23.1 \%$ vs $12.6 \%$, $P=0.036)$. Sarcopenia had no relation with the rate of infection code recorded in patients $<65$ years. Sarcopenic patients $\geqslant 65$ years also had infections more frequently compared with nonsarcopenic patients $\geqslant 65$ years $(29.6 \% v s 8.8 \%, P=0.005)$. In the multiple logistic regression analysis, sarcopenia was independently predictive of postoperative infections in a multivariate analysis including sex, cancer stage and tumour site (odds ratio (OR): 4.6; 95\% confidence interval (CI): 1.5-13.9) (Table 4). Age was a significant predictor of infection at the univariate level, but was not significant in any multivariate model in which sarcopenia was also included. We also assessed all of the individual major 
comorbidities as well as the presence of obstruction for relationship with infection. We did not find any significant relationship with infection at the univariate level. Finally, neither visceral, subcutaneous nor total lumbar adipose tissue significantly related to postoperative infection or rehabilitation.
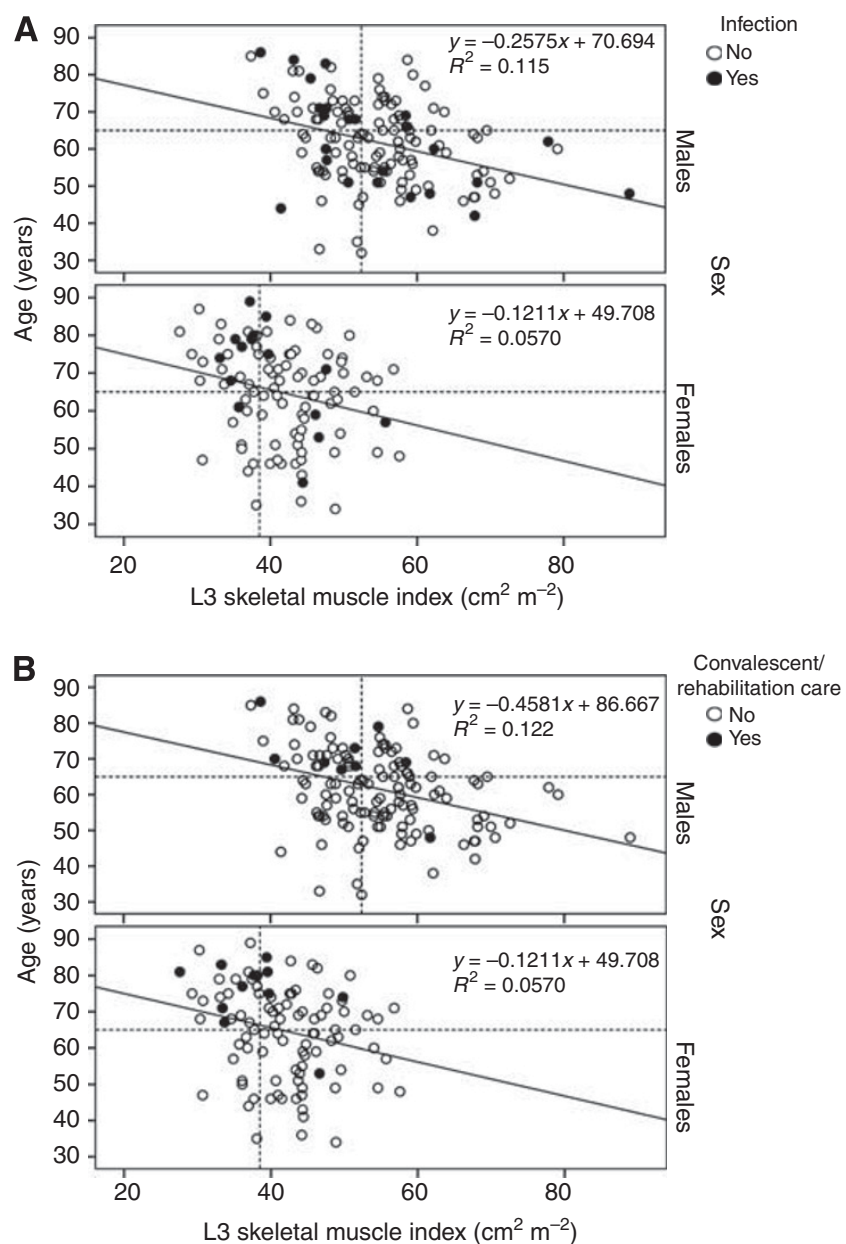

Figure I Scatterplots depicting the relationship between age and skeletal muscle index, and the incidence of $(\mathbf{A})$ infection and (B) convalescent/rehabilitation care in patients undergoing primary colorectal cancer tumour resection. Solid circles $(\mathbf{O})$ are patients who had the negative outcome (i.e., infection or convalescent care) and the hollow circles $(O)$ are patients who did not have the outcome. Horizontal solid line- age 65 years. Vertical solid line - gender-specific sarcopenia cutpoints (Prado et al, 2008). Equation for each panel is the regression line of best fit.
Need for additional rehabilitation Excluding the patient who died in the index hospitalisation, 21 patients (9.0\%) required inpatient hospitalisation for rehabilitation and 19 of those patients $(90 \%)$ were $\geqslant 65$ years (Figure $1 B$ ). The following ICD-10 codes were found relating to use of inpatient rehabilitation care: convalescence following surgery or combined treatment (Z54.0,

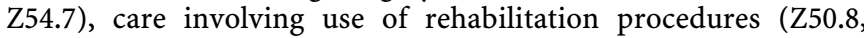
Z50.9), or other physical therapy (Z50.1). Inpatient rehabilitation care occurred in the same hospital as the index surgery in $14 \%$ of cases, and in a nursing home or rehabilitation hospital in $86 \%$ of cases. Length of stay following transfer to a rehabilitation facility was $14.8 \pm 10.9$ days. Inpatient rehabilitation care was more common for sarcopenic patients overall $(14.3 \%$ vs $5.6 \%$; $P=0.024)$ as well as for those $\geqslant 65$ years $(24.1 \%$ vs $10.7 \%$, $P=0.06$ ). In patients $\geqslant 65$ years, in a multivariate analysis including sex, cancer stage and tumour site, the risk of convalescent care was higher in patients with sarcopenia (OR: $3.1,95 \%$ CI 1.04, 9.4) (Table 2). Age was a significant predictor of rehabilitation at the univariate level, but was not significant in any multivariate model in which sarcopenia was also included. Comorbidities and obstruction were not significantly related to rehabilitation care.

Length of stay (LOS) An accurate LOS related to recovery following colorectal cancer surgery could not be calculated for five patients who were excluded from this analysis. Four of those patients had a code in their relevant record(s), indicating they were on a waiting list for admission elsewhere (ICD-10: Z75.1), and another patient had a hip replacement during the index surgical admission. Considering the LOS of the index hospitalisation, the mean overall LOS was $11.6 \pm 7.4$ days in all patients and $13.7 \pm 8.4$ days in those $\geqslant 65$ years $(P<0.001)$. Patients without sarcopenia had an index hospitalisation LOS of $10.6 \pm 6.2$ days compared with $13.2 \pm 8.8$ days in patients with sarcopenia $(P=0.012)$. In patients $\geqslant 65$ years, sarcopenic patients had a LOS of $15.7 \pm 9.8$ days compared with $11.8 \pm 6.4$ days for non-sarcopenic patients $(P=0.018)$

\section{DISCUSSION}

We conducted specific quantification of skeletal muscle by CT image analysis in patients admitted for colorectal cancer resection. Using this approach, we show that sarcopenia is prevalent in this population, the depletion of muscle mass is a risk factor for perioperative infection, and sarcopenia is associated with increased health service utilisation, in the form of increased LOS and requirements for prolonged rehabilitation care. This was particularly the case with older patients. Within the limitations of the use of administrative health data, it seems clear that depletion

Table 3 The relationship between sarcopenia and outcomes of hospitalisation

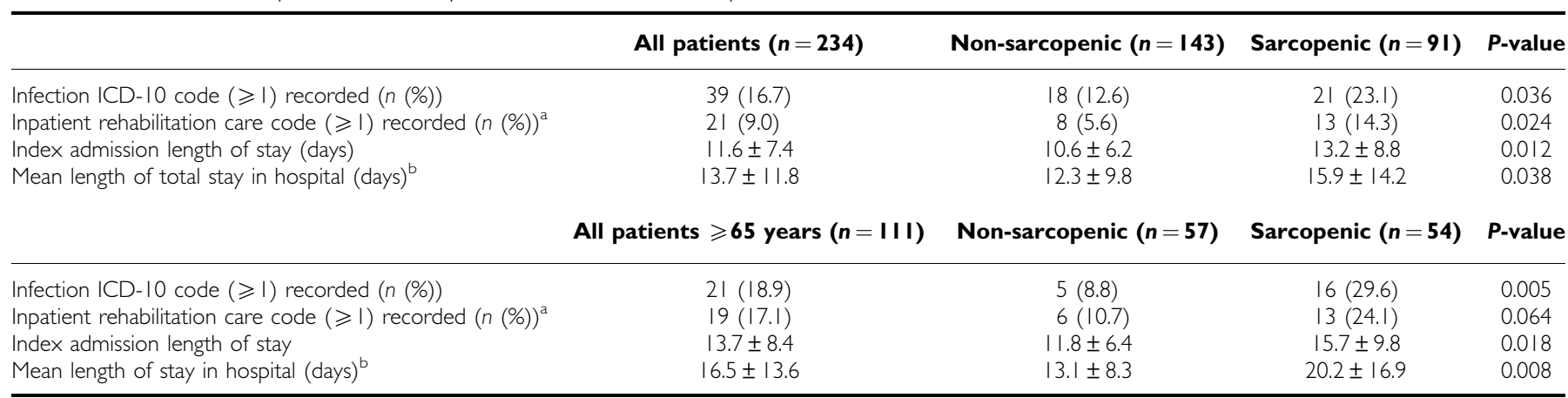

Abbreviation: ICD = International Classification of Disease. ${ }^{a}$ One patient who died in hospital was not considered in the analysis for inpatient rehabilitation care. ${ }^{b}$ Five patients were ineligible for this analysis as outlined in the Results section. 
Table 4 Multivariate logistic regression for predictors of inpatient rehabilitation/convalescent care and infection in patients over 65 years of age undergoing colorectal cancer surgery

\begin{tabular}{|c|c|c|c|c|c|c|c|c|}
\hline & \multicolumn{4}{|c|}{ Infection } & \multicolumn{4}{|c|}{ Convalescent/rehabilitation care } \\
\hline \multicolumn{9}{|l|}{ Sarcopenia } \\
\hline No & 1.0 & & 1.0 & & 1.0 & & 1.0 & \\
\hline Yes & $4.4(1.5,13.0)$ & 0.008 & $4.6(1.5,13.9)$ & 0.007 & $2.6(0.92,7.6)$ & 0.070 & $3.1(1.04,9.4)$ & 0.043 \\
\hline \multicolumn{9}{|l|}{ Sex } \\
\hline Male & I.I $(0.43,2.8)$ & 0.84 & $0.99(0.36,2.7)$ & 0.98 & $0.68(0.25,1.8)$ & 0.45 & $0.65(0.22,1.9)$ & 0.43 \\
\hline \multicolumn{9}{|l|}{ Cancer stage } \\
\hline$\|$ & 1.0 & & 1.0 & & 1.0 & & 1.0 & \\
\hline III & $0.63(0.21,1.9)$ & & $0.63(0.20,2.0)$ & & $1.5(0.46,4.6)$ & & $1.6(0.48,5.5)$ & \\
\hline IV & $0.45(0.14,1.5)$ & 0.42 & $0.42(0.12,1.5)$ & 0.40 & $0.60(0.16,2.4)$ & 0.40 & $0.74(0.18,3.1)$ & 0.48 \\
\hline \multicolumn{9}{|l|}{ Primary tumour site } \\
\hline
\end{tabular}

Abbreviations: $\mathrm{Cl}=$ confidence interval; $\mathrm{OR}=$ odds ratio.

of skeletal muscle mass in an increasingly elderly population of cancer patients will have ramifications for the use of a variety of health-care services. Future prospective studies are required to confirm these results and to determine longer term outcomes and risks, the potential additional use of outpatient health services such as home care, as well as impact on quality of life and exact costs associated with sarcopenia.

Sarcopenia has been associated with reduced survival and chemotherapy treatment toxicity (Prado et al, 2008, 2009, 2011; Antoun et al, 2010; van Vledder et al, 2012). Peng et al (2011) examined sarcopenia in relation to outcome of cancer surgery (liver resection for colorectal liver metastasis). Total psoas muscle area on computed tomography was used to assess sarcopenia, and by this criterion sarcopenia was associated with an increased risk of major postoperative complications in multivariate analysis (OR 3.12; $P=0.02$ ). Patients with sarcopenia also had longer hospital stays (6.6 vs 5.4 days; $P=0.03)$ and a higher chance of an extended intensive care unit stay ( $>2$ days; $P=0.004$ ). Awad et al (2012) did not find an association between sarcopenia and hospital LOS in 47 patients with gastroesophageal cancer patients. Further prospective studies are required to confirm and expand the findings available to date. In prospective work, additional details may be acquired, which may be related to skeletal muscle mass. For example, within the index hospitalisation, glucose control would be an interesting topic for a future study, because muscle is a quantitatively important site of glucose disposal. Post-discharge outcomes such as physical functioning, use of outpatient rehabilitation services and return to work will also be of interest.

Sarcopenia is not restricted to individuals who appear thin or wasted. Indeed, our patient population was characterised by heavy body weights with a mean BMI $\left(28.5 \mathrm{~kg} \mathrm{~m}^{-2}\right)$ in the upper end of overweight. A conventionally understood risk for poor outcomes of surgery, BMI $<18.5 \mathrm{~kg} \mathrm{~m}^{-2}$ (clinically underweight) is increasingly rare in contemporary populations of cancer patients. The results here are in concordance with observations in patients with gastrointestinal malignancies and non-small cell lung cancer (Prado et al, 2008; Baracos et al, 2010) who have simultaneously heavy body weight and severe muscle depletion. Sarcopenia, as opposed to generalised overall wasting, is often an occult condition, Sarcopenia is hidden from view by a mantle of adipose tissue and it is important that it is easy to be unaware of this deterioration of the muscle mass, without the use of diagnostic imaging or some other approach (e.g., dual energy X-ray absorptiometry) for its specific detection. Computed tomography images used for planning surgery are a convenient resource to detect sarcopenia. As these images are routinely available in the clinical record, no incremental testing is needed to make the relevant assessments. The significant prevalence of sarcopenia at presentation for surgery suggests that muscle atrophy occurs prior to cancer diagnosis and surgery. Neither the point at time of onset of muscle loss nor the exact aetiology, are known. However, sarcopenia is often attributed to aging, and indeed our patients with sarcopenia were 5 years older on average. Considering cancer, the primary diagnosis, and its role in the generation of sarcopenia, the dominant effect was that of obstruction, which was significantly more common in patients with sarcopenia, whereas cancer site or stage was less important. After diagnosis and over the course of treatment, muscle loss continues. Our earlier work (Lieffers et al, 2009) demonstrated the progressive increase in the rate of muscle wasting in colorectal cancer patients during the year preceding death. Sarcopenia may also potentially be explained by comorbid conditions, as several chronic diseases are characterised by wasting. Here, the sarcopenic patients had a significantly higher number of comorbidities. Sarcopenia is also a consequence of inactivity and bed rest (Coker and Wolfe, 2012) and besides being generally more ill, sarcopenic patients had already spent more total time in hospital in the year preceding their colorectal cancer surgery, than non-sarcopenic patients. It is likely that all of the aforementioned influences contribute to the eventual development of severe muscle depletion, and their respective importance may be difficult to specifically quantify.

Ideally, cutpoints for sarcopenia should be solved within each specific patient population and BMI category (obese, overweight, normal weight, underweight). A much larger sample would be required to undertake cutpoint analysis by sex and by BMI. Until data are assembled in sufficient number, we note that the cutpoints used here (Prado et al, 2008) have subsequently proven to be independent predictors of survival and treatment toxicity in cancer patients (Prado et al, 2009, 2011) as well as independently predictive of survival in cirrhosis patients (Montano-Loza et al, 2012). 
Clinical research on cancer-associated muscle wasting is growing and several treatments are in development (Dodson et al, 2011). Therapeutic approaches are predicated on participation of key molecules in signalling muscle catabolism, and the hypothesis that wasting is reversible by specific interventions targeting these signals. Given the relatively long expected survival of patients referred for colorectal cancer resection, they may be a suitable candidate population for testing these approaches and the prediction that reversal of sarcopenia may confer multiple benefits to patients and the health-care system.

\section{REFERENCES}

Antoun S, Baracos VE, Birdsell L, Escudier B, Sawyer MB (2010) Low body mass index and sarcopenia associated with dose-limiting toxicity of sorafenib in patients with renal cell carcinoma. Ann Oncol 21(8): 1594-1598

Awad S, Tan BH, Cui H, Bhalla A, Fearon KC, Parsons SL, Catton JA, Lobo DN (2012) Marked changes in body composition following neoadjuvant chemotherapy for oesophagogastric cancer. Clin Nutr 31: 74-77

Baracos V, Caserotti P, Earthman CP, Fields D, Gallagher D, Hall KD, Heymsfield SB, Müller MJ, Rosen AN, Pichard C, Redman LM, Shen W, Shepherd JA, Thomas D (2012) Advances in the science and application of body composition measurement. JPEN J Parenter Enteral Nutr 36(1): 96-107

Baracos VE, Reiman T, Mourtzakis M, Gioulbasanis I, Antoun S (2010) Body composition in patients with non-small cell lung cancer: a contemporary view of cancer cachexia with the use of computed tomography image analysis. Am J Clin Nutr 91: 1133S-1137S

Baumgartner RN, Koehler KM, Gallagher D, Romero L, Heymsfield SB, Ross RR, Garry PJ, Lindeman RD (1998) Epidemiology of sarcopenia among the elderly in New Mexico. Am J Epidemiol 147: 755-763

Coker RH, Wolfe RR (2012) Bedrest and sarcopenia. Curr Opin Clin Nutr Metab Care 15(1): 7-11

Cosquéric G, Sebag A, Ducolombier C, Thomas C, Piette F, Weill-Engerer S (2006) Sarcopenia is predictive of nosocomial infection in care of the elderly. Br J Nutr 96(5): 895-901

Dodson S, Baracos VE, Jatoi A, Evans WJ, Cella D, Dalton JT, Steiner MS (2011) Muscle wasting in cancer cachexia: clinical implications, diagnosis, and emerging treatment strategies. Annu Rev Med 62: 265-279

Fearon K, Strasser F, Anker SD, Bosaeus I, Bruera E, Fainsinger RL, Jatoi A, Loprinzi C, MacDonald N, Mantovani G, Davis M, Muscaritoli M, Ottery F, Radbruch L, Ravasco P, Walsh D, Wilcock A, Kaasa S, Baracos VE (2011) Definition and classification of cancer cachexia: an international consensus. Lancet Oncol 12(5): 489-495

Lieffers JR, Baracos VE, Winget M, Fassbender K (2011) A comparison of Charlson and Elixhauser comorbidity measures to predict colorectal cancer survival using administrative health data. Cancer 117(9): 1957-1965

Lieffers JR, Mourtzakis M, Hall KD, McCargar LJ, Prado CM, Baracos VE (2009) A viscerally driven cachexia syndrome in patients with advanced colorectal cancer: contributions of organ and tumor mass to whole-body energy demands. Am J Clin Nutr 89(4): 1173-1179

MacDonald AJ, Greig CA, Baracos V (2011) The advantages and limitations of cross-sectional body composition analysis. Curr Opin Support Palliat Care 5(4): 342-349

\section{CONCLUSION}

Sarcopenia predicts infections, inpatient rehabilitation care and consequently a longer LOS, in colorectal cancer patients.

\section{ACKNOWLEDGEMENTS}

We thank Dr Sunita Ghosh for statistical advice, and Charlotte King, Lisa Martin, and Nina Esfandiari for assistance with the databases used for this study. This work was funded by Alberta Cancer Research Institute, Alberta Health Services, Canadian Institutes of Health Research and Alberta Cancer Foundation.

Montano-Loza AJ, Meza-Junco J, Prado CM, Lieffers JR, Baracos VE, Bain VG, Sawyer MB (2012) Muscle wasting is associated with mortality in patients with cirrhosis. Clin Gastroenterol Hepatol 10(2): 166-173

Mourtzakis M, Prado CM, Lieffers JR, Reiman T, McCargar LJ, Baracos VE (2008) A practical and precise approach to quantification of body composition in cancer patients using computed tomography images acquired during routine care. Appl Physiol Nutr Metab 33(5): 997-1006

Peng PD, van Vledder MG, Tsai S, de Jong MC, Makary M, Ng J, Edil BH Wolfgang CL, Schulick RD, Choti MA, Kamel I, Pawlik TM (2011) Sarcopenia negatively impacts short-term outcomes in patients undergoing hepatic resection for colorectal liver metastasis. $H P B$ 13(7): 439-446

Pichard C, Kyle UG, Morabia A, Perrier A, Vermeulen B, Unger P (2004) Nutritional assessment: lean body mass depletion at hospital admission is associated with an increased length of stay. Am J Clin Nutr 79(4): 613-618

Prado CM, Antoun S, Sawyer MB, Baracos VE (2011) Two faces of drug therapy in cancer: drug-related lean tissue loss and its adverse consequences to survival and toxicity. Curr Opin Clin Nutr Metab Care 14(3): 250-254

Prado CM, Baracos VE, McCargar LJ, Reiman T, Mourtzakis M, Tonkin K, Mackey JR, Koski S, Pituskin E, Sawyer MB (2009) Sarcopenia as a determinant of chemotherapy toxicity and time to tumor progression in metastatic breast cancer patients receiving capecitabine treatment. Clin Cancer Res 15(8): 2920-2926

Prado CM, Lieffers JR, McCargar LJ, Reiman T, Sawyer MB, Martin L, Baracos VE (2008) Prevalence and clinical implications of sarcopenic obesity in patients with solid tumours of the respiratory and gastrointestinal tracts: a population-based study. Lancet Oncol 9(7): 629-635

Quan H, Sundararajan V, Halfon P, Fong A, Burnand B, Luthi JC, Saunders LD, Beck CA, Feasby TE, Ghali WA (2005) Coding algorithms for defining comorbidities in ICD-9-CM and ICD-10 administrative data. Med Care 43(11): 1130-1139

Shen W, Punyanitya M, Wang Z, Gallagher D, St-Onge MP, Albu J, Heymsfield SB, Heshka S (2004) Total body skeletal muscle and adipose tissue volumes: estimation from a single abdominal cross-sectional image. J Appl Physiol 97: 2333-2338

van Vledder MG, Levolger S, Ayez N, Verhoef C, Tran TC, Ijzermans JN (2012) Body composition and outcome in patients undergoing resection of colorectal liver metastases. Br J Surg 99(4): 550-557

This work is published under the standard license to publish agreement. After 12 months the work will become freely available and the license terms will switch to a Creative Commons Attribution-NonCommercial-Share Alike 3.0 Unported License. 